\title{
A RELAÇÃo BREVE DE FREI PAULO DO ROSÁRIO: RELATOS SOBRE O PRIMEIRO ATAQUE HOLANDÊS À CAPITANIA DA PARAÍBA (1631) ${ }^{1}$
}

Leandro Vilar Oliveira ${ }^{2}$

\section{Introdução}

Paulo do Rosário nasceu em data incerta na cidade do Porto, em Portugal, vindo a falecer em 10 de janeiro de 1655, no Mosteiro de Bustelo, Penafiel ${ }^{3}$. Entrou para a Ordem dos Beneditinos em 22 de agosto de 1601, no Convento de São Tirso. Ao longo de sua vida exerceu funções como abade e comissário em distintos mosteiros e igrejas de Portugal e no Brasil, atuando nas capitanias da Bahia, Pernambuco e Paraíba ${ }^{4}$. No ano de 1631, encontrava-se de volta ao Brasil, exercendo a função de Comissário Provincial da Ordem dos Beneditinos. Na ocasião, frei Paulo do Rosário estava exercendo suas atividades na Capitania da Paraíba, quando notícias sobre um possível ataque dos holandeses a capitania, chegaram ao conhecimento do governador e capitão-mor Antônio de Albuquerque Maranhão ${ }^{5}$.

Rosário o qual ainda não havia concluído suas obrigações na Paraíba, decidiu permanecer na capitania, mesmo com a ameaça de guerra, a qual veio a ocorrer em dezembro daquele ano, quando os holandeses apareceram ao longo da costa do Cabo Branco em 4 de dezembro de 1631. Os portugueses, espanhóis, colonos e indígenas já estavam aguardando a vinda deles. O general Matias de Albuquerque, responsável pelo comando das tropas de defesa brasileira em Pernambuco, encaminhou ordens ao governador da Paraíba, para que fortificasse as defesas da sua

${ }^{1}$ Esse trabalho é baseado em algumas das pesquisas realizadas para a dissertação de mestrado OLIVEIRA, Leandro Vilar. Guerras luso-holandesas na Capitania da Paraíba (1631-1634): um estudo documental e historiográfico. 2016. 255f. Dissertação (Mestrado em História e Cultura Histórica) Programa de Pós-Graduação em História, Universidade Federal da Paraíba, João Pessoa, 2016.

${ }^{2}$ Doutorando em Ciências das Religiões (UFPB), Mestre em História e Cultura Histórica (UFPB), membro pesquisador do Núcleo de Estudos Vikings e Escandinavos (NEVE). E-mail: vilarleandro@hotmail.com.

${ }_{3}^{3}$ LINS, Guilherme Gomes da Silveira d'Ávila. Os Beneditinos na Paraíba. Uma contribuição para a sua história com ênfase nos seus primórdios. João Pessoa: Edição do Autor, 2014, p. 128.

4 MACHADO, Diogo Barbosa. Bibliotheca Lusitana histórica, crítica e cronológica: na qual se compreende a noticia dos autores portugueses, e das obras, que compuzerão desde o tempo da promulgação da Ley da Graça até o tempo presente, t. I. Lisboa: Officina Ignacio Rodrigues, 1741. 4v, p. 533.

${ }^{5}$ Antônio de Albuquerque Maranhão (?-1667) era o filho mais velho de Jerônimo de Albuquerque, o Maranhão e D. Catharina Pinheiro Feio. Por parte desse casamento teve mais dois irmãos: Matias e Jerônimo. Foi brevemente governador da Capitania do Maranhão entre 1618 e 1619, sucedendo o seu pai. Foi nomeado em 09 de agosto de 1622 ao cargo de capitão-mor e governador da Paraíba, contudo tomou posse em data incerta por volta de 1627 e manteve-se no cargo até 1634, quando em dezembro ao ser derrotado pelos holandeses, acabou deixando a capitania, retornando depois para Portugal. LINS, Guilherme Gomes da Silveira d'Ávila. O fracasso holandês na Capitania da Paraíba em 1631. 2 ed. João Pessoa: Edição do Autor, 2007, p. 51-54. 
capitania e reunisse tropas para a guerra, pois era quase certeza que um ataque ocorreria ainda naquele ano. Assim, frei Paulo do Rosário junto a outros freis, seguiu para o Forte do Cabedelo donde testemunhou, ao longo de uma semana, 5 a 12 de dezembro, os conflitos que ali se sucederam.

O seu testemunho posteriormente foi escrito e tornou-se um opúsculo intitulado Relaçam Breve, e Verdadeira da memoravel victoria, que ouue o Capitão môr da Capitania da Paraiua Antonio de Albuquerque, dos Rebeldes de Olanda, que são vinte nâos de guerra, \& vinte \& sete lanchas: pretenderão ocupar esta praça de sua Magestade, trazendo nelas pera o efeito dous mil homens de guerra escolhidos, a fora a gente do mar. Publicado em setembro de 1632, em Lisboa.

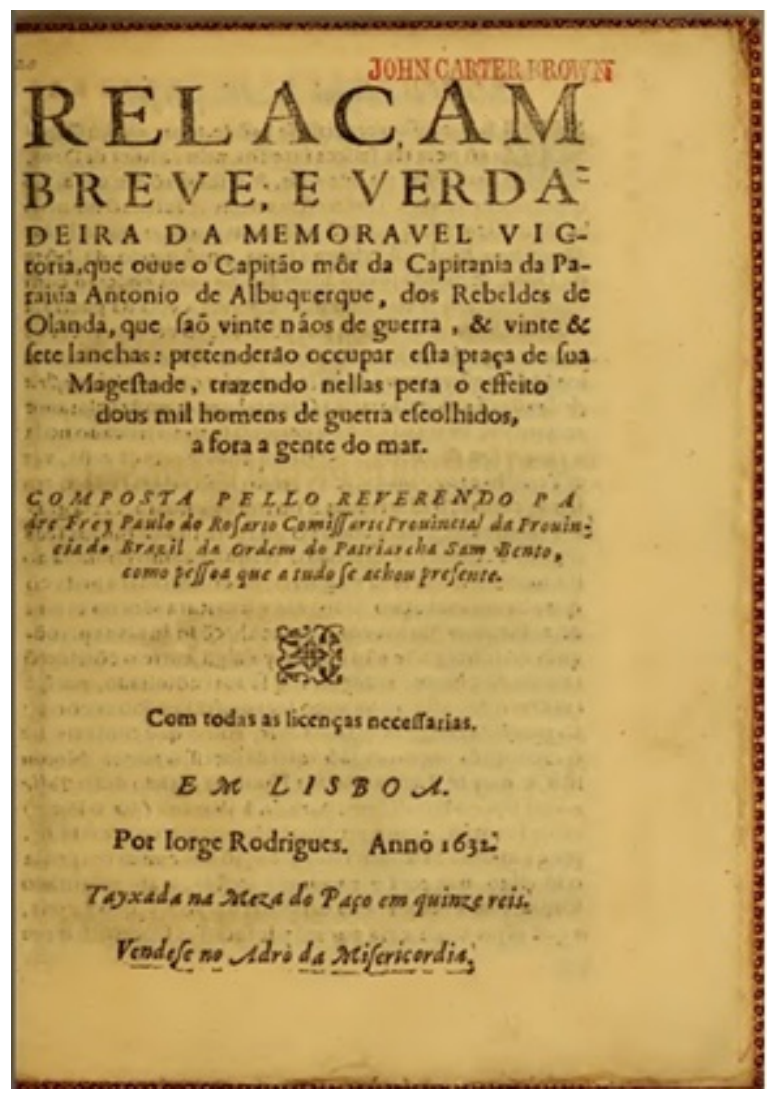

Figura 1: Frontispício da Relaçam Breve e Verdadeira de Frei Paulo do Rosário, 1632.

Embora seja uma obra bastante antiga e escrita logo em seguida aos acontecimentos narrados, além de consistir num livro cujo autor foi testemunha direta dos eventos citados, sendo uma das poucas fontes primárias que se tem conhecimento a respeito da primeira expedição holandesa à Capitania da Paraíba, ainda assim, por muito tempo a Relaçam Breve e Verdadeira foi pouco conhecida pelos historiadores portugueses e brasileiros.

Mas esse pouco conhecimento não significou que o livro passou despercebido. No século XIX, o historiador Francisco Adolfo de Varnhagen, em sua primeira edição de História Geral do Brazil (1854), menciona em nota de rodapé o livro de frei Paulo do 
Rosário ${ }^{6}$. Outros historiadores portugueses também mencionariam a obra e no século $\mathrm{XX}$, José Honório Rodrigues, conhecido por seu trabalho de coletar, transcrever e traduzir documentos diretamente de arquivos dos arquivos holandeses, elaborou listas bibliográficas sobre as fontes acerca do Brasil holandês, e menciona o livro Relaçam Breve e Verdadeira algumas vezes ${ }^{7}$.

No final do século XX, o pesquisador do IHGP (Instituto Histórico e Geográfico Paraibano) Guilherme Gomes da Silveira d'Ávila Lins começou a investigar a respeito da produção histórica sobre o Brasil holandês referente à história paraibana, realizando um levantamento bibliográfico dos livros produzidos no século XVII, no que resultou na identificação de dezesseis autores que mencionavam a obra de frei Paulo do Rosário desde a época de seu lançamento ${ }^{8}$.

Mais recentemente, no ano de 2013, os autores Tarcízio Dinoá Medeiros e Jorge Brito publicaram a transcrição do livro Relaçam Breve e Verdadeira, para a atual norma ortográfica da Língua Portuguesa, como também disponibilizaram um facsímile da obra original, além de trazerem uma introdução contando um pouco da vida e obra do frei, assim como, traçando um breve levantamento bibliográfico. A nova versão foi intitulada Relato de 1632 de Frei Paulo do Rosário Sobre a Primeira Invasão Holandesa da Paraíba9.

Por tais menções percebe-se que o livro de Rosário não passou despercebido, embora pouca atenção the foi dada na historiografia brasileira e paraibana, algo comentado por Rodrigues, Lins, Medeiros e Brito. Mas o que tornaria esse livro importante de ser conhecido, para além de ser uma fonte primária?

A obra embora seja breve, nos fornece detalhes que não constam em outros trabalhos da época que abordam o mesmo acontecimento como História ou Anais da Companhia Privilegiada das Índias Ocidentais (1644) de Joannes de Laet ${ }^{10}$, importante diretor da WIC (West-Indische Compagnie). As Memórias diárias da Guerra do Brasil (1654), escrito Duarte de Albuquerque Coelho ${ }^{11}$, governador de Pernambuco, e o Diário de um soldado da Companhia das Índias Ocidentais (1677) de Ambrósio Richshoffer ${ }^{12}$, soldado que lutou pela WIC. Neste aspecto, algumas

${ }^{6}$ VARNHAGEN, Francisco A. de. História Geral do Brazil, tomo I. Rio de Janeiro: E H Lammaert, 1854, $2 v$, p. 366. Varnhagen voltou a fazer breves referências a frei Paulo do Rosário na segunda edição de História Geral do Brazil e no livro História das Lutas contra os Holandeses no Brasil (1872).

${ }^{7}$ RODRIGUES, José Honório. Historiografia e bibliografia do domínio holandês no Brasil. Rio de Janeiro: Imprensa Nacional, 1949, p. 191.

8 LINS, Guilherme Gomes d'Ávila. Bibliografia das obras impressas em Portugal pelo tipógrafo Jorge Rodrigues entre 1598 e 1642. 2a ed, revista e ampliada. Recife: Editora da UFPE, 2009.

${ }^{9}$ OLIVEIRA, Leandro Vilar. Guerras luso-holandesas..., p. 45-46.

10 Joannes de Laet (1581-1649) foi comerciante belga, erudito e um dos diretores da WIC pela Câmara de Amsterdã, a principal da companhia. À serviço da WIC redigiu obras de história e geografia. BREMMER JR, Rolph H. "The correspondence of Johannes de Laet (1581-1649): as mirror of his life". LIAS, n. 25, v. 2, p. 139-165, 1998.

${ }^{11}$ Duarte de Albuquerque Coelho (1591-1658) foi um nobre português, ocupando o cargo de quarto capitão donatário de Pernambuco. Recebeu da Coroa Espanhola os títulos de Conde de Pernambuco e Marques de Basto. Redigiu um importante livro entre 1630 e 1638, período que esteve em Pernambuco tentando expulsar os holandeses. Era irmão mais velho do general Matias de Albuquerque Coelho. COSTA, F. A. Pereira da. "Donatários de Pernambuco e governadores e seus loco-tenentes". RIAGP, n. 48, p. 3-28, 1896.

${ }^{12}$ Ambrósio Richshoffer (1612-?) nasceu em Estrasburgo, era filho de comerciantes. Aos 17 anos se alistou na WIC, servindo na companhia até 1632. No ano de 1633 ingressou no corpo de mosqueteiros 
informações narradas por Paulo do Rosário são confirmadas no relato de Ambrósio Richshoffer, mas estão ausentes nas obras de Laet e Coelho, pois ambos não foram testemunhas diretas dos conflitos, diferente de Richshoffer que lutou no campo de batalha e de Rosário que assistiu o conflito a partir do Forte do Cabedelo.

Não obstante, a Relaçam Breve e Verdadeira além de narrar os eventos da primeira expedição à Capitania da Paraíba, o seu autor também narrou - embora de forma bem mais lacônica - a primeira expedição dos holandeses à Capitania do Rio Grande (do Norte), empresa iniciada na véspera de Natal de 1631, com o intuito de conquistar o Rio Grande, mas que fracassou, tornando-se no fim, uma missão de exploração do território ${ }^{13}$.

Mas além desse valor singular a respeito de informações históricas sobre esta guerra, a obra de frei Paulo do Rosário também nos fornece elementos relacionados ao contexto histórico e literário de sua época: o discurso religioso relacionado às guerras entre católicos e protestantes que ocorriam na Europa ${ }^{14}$; o discurso panegírico de enaltecimento do governador Antônio de Albuquerque Maranhão; o discurso de traição dos holandeses a Coroa Espanhola ${ }^{15}$. Tais características do discurso de Rosário serão aqui comentadas, além das informações históricas sobre a primeira expedição à Capitania da Paraíba ${ }^{16}$, e para isso realizaremos uma análise literária e de discurso, sendo que o livro possui basicamente três discursos: o religioso, o político e o panegírico.

do rei Luís XIII da França. Se desconhece mais dados da sua vida. Publicou seu diário na velhice. MIRANDA, Bruno Romero Ferreira. Gente de Guerra: origem, cotidiano e resistência dos soldados do exército da Companhia das Índias Ocidentais no Brasil (1630-1654). Recife: Editora UFPE, 2014.

${ }^{13}$ Um dos fatores apontados por Rosário e Richshoffer para a desistência de um ataque à Natal, deveuse a condição do Forte dos Reis Magos está bem estruturado e munido de homens, munição e alimentos. Além de que tropas paraibana foram enviadas para apoiá-los. OLIVEIRA, Leandro Vilar. Guerras luso-holandesas..., p. 46.

${ }^{14}$ As guerras religiosas europeias se iniciaram no século XVI por volta de 1560 e durando até cerca de 1660 , totalizando um século de sangrentos conflitos motivados pelo embate entre católicos e protestantes, pois os católicos não aceitavam a Reforma Protestante e por sua vez, os protestantes acusavam os católicos de terem se desviado dos "verdadeiros" ensinamentos de Cristo. Que a Igreja Católica estava corrompida. A Noite de São Bartolomeu (1572) foi um dos acontecimentos mais sangrentos dessas guerras, um massacre que vitimou milhares de protestantes na França. CORVISIER, André. Armies and societies in Europe, 1494-1789. Translated by Abigail T. Siddall. Bloomington: Indiana University Press, 1979, p. 4-6.

${ }^{15}$ A traição que frei Paulo do Rosário se referia, dizia respeito a Guerra dos Oitenta Anos (1568-1648). Inicialmente a região das Dezessete Províncias (atualmente Holanda e Bélgica a grosso modo) pertenciam ao rei Filipe II da Espanha. Todavia, alguns nobres e burgueses das províncias do Norte estavam insatisfeitos com a política autoritária, conservadora e intolerante do monarca espanhol, no que resultou na separação de sete províncias, as quais declararam independência do governo espanhol, vindo a se tornarem a República das Sete Províncias Unidas dos Países Baixos, popularmente chamada de Holanda. GELDEREN, Martin Van. The political thought of the Dutch Revolt: 1555-1590. New York: Cambridge University Press, 1992, p. 32-33.

${ }^{16}$ A segunda expedição ocorreu entre 25-27 de fevereiro de 1634. A terceira expedição aconteceu entre 2-31 de dezembro de 1634, cujo resultado culminou com a conquista da Capitania da Paraíba. 


\section{A narrativa}

Sabemos que frei Paulo do Rosário foi testemunha ocular dos acontecimentos ocorridos em dezembro de 1631, na chamada "Batalha do Cabedelo", no entanto, o frei não deixou claro os motivos que o levaram a redigir esta obra. Teria sido por causa de questões religiosas, políticas ou pessoais? Nota-se que no seu discurso ele exalta o capitão-mor Antônio de Albuquerque Maranhão, mas no final da obra exalta a valentia dos soldados portugueses e espanhóis nesta guerra. Por outro lado, ele não dedica à obra a Coroa, nem a Igreja ou ao povo português. E embora traga o nome de Antônio de Albuquerque no título, não há uma dedicatória explícita ao capitãomor da Paraíba.

No que se refere ao motivo ou motivos que levaram frei Paulo do Rosário a redigir sua relação, não possuímos muitas informações e certezas, mas de acordo com Lígia Bellini ${ }^{17}$, na Portugal dos séculos XVII e XVIII, os clérigos enxergavam como um de seus deveres o registro escrito, o qual Palomo escreveu o seguinte:

El estrecho vínculo que existió entre misión y escritura viene a subrayar, por un lado, el papel que los miembros del clero pudieron llegar a desempeñar, mediante sus textos, en la construcción y configuración de uno y otro imperio. Al margen de la labor específica de evangelización, las propias funciones que desempeñaron en el campo misionero y en el seno de las nuevas sociedades constituidas en los espacios coloniales, les otorgaron a menudo una condición - no siempre puesta em valor por la historiografia - de "prácticos" o de "expertos" del imperio; condición que dejaron patente en memoriales, tratados políticos, cartas, crónicas, relaciones de misión, etc. (pero también en "textos" de naturaleza visual y cartográfica), por medio de los cuales trataron de articular proyectos político-religiosos, saberes, percepciones e intereses de las realidades locales, contribuyendo directa $\mathrm{o}$ indirectamente al desarrollo de aquellas dinámicas de naturaleza política, social y cultural que acompañaron y caracterizaron las experiencias imperiales de las monarquias peninsulares ${ }^{18}$.

Sendo os religiosos os principais membros alfabetizados da população e estando alguns envolvidos nas atividades missionárias que os levavam a ter que viajar para outros países e continentes, alguns desses religiosos, como Palomo (2014) apontou, passaram a atuar como "diplomatas", tratando de assuntos de ordem política e não

\footnotetext{
${ }^{17}$ BELLINI, Lígia. "Cultura escrita, oralidade e gênero em conventos portugueses (séculos XVII e XVIII)". Revista Tempo, n. 29, v. 15, p. 211-233, 2011, p. 216.

${ }^{18}$ PALOMO, Federico. Introducción: Clero y cultura escrita en el mundo ibérico de la Edad Moderna. Cuadernos de Historia Moderna - Anejo XIII - La memoria del mundo: clero, erudución y cultura escrita em el mundo ibérico (siglos XVI-XVIII), p. 11-26, 2014, p. 12.
} 
apenas religiosa, como também o fato de serem letrados, se tornaram cronistas. Relatando sobre o que viram e ouviram nas terras que visitaram.

Febvre e Martin $^{19}$ também assinalam que nos séculos XV ao XVI a grande maioria de obras impressas, eram produzidas por clérigos, como trabalhos teológicos, traduções de obras da Antiguidade, trabalhos de filosofia e direito canônico, relatos históricos, crônicas, etc. No século XVII, essa produção eclesiástica decaiu um pouco, mas ainda se manteve até o XVIII. Pelo fato da Relaçam Breve e Verdadeira ter sido escrita por um religioso, ela se encaixa nessa produção eclesiástica mencionada pelos dois historiadores, os quais também salientam que até o começo do XVII, livros produzidos por clérigos com temas religiosos, eram garantia de venda certa, embora que a obra de Rosário não fosse necessariamente um trabalho de cunho teológico, mas mantinha um discurso religioso.

Não obstante, além dessa procura dos clérigos em difundir suas produções, eles viam como um dever preservar a história dos acontecimentos, logo, muitos clérigos escreviam crônicas, relações, histórias, anais ou compilavam outras obras. Isso fica evidente quando notamos que alguns livros como História do Brazil (1627) de frei Vicente do Salvador, além das crônicas sobre o período holandês, feitas por Manoel Calado, Rafael de Jesus e Simão de Vasconcelos, foram obras escritas por religiosos. No caso, os:

Clérigos y religiosos - cabe recordarlo - siguieron ocupando un lugar central en el campo de la cultura escrita altomoderna. No sólo se dedicaron afanosamente a la tarea de escribir y componer textos, como fueron también lectores ávidos de las obras que conservaban en las bibliotecas de cabildos, conventos y colegios; aquéllas ciertamente que en la época reunirían acervos más importantes. No faltaron siquiera hombres de Iglesia que se significaron por su erudición y su bibliofilia, reuniendo notables coleciones particulares de libros que, en ocasiones, funcionaron para sus coetáneos como referentes del conocimiento erudito y de la actividad literaria. El clero mantuvo una posición de particular relevancia en aquellos espacios que, como universidades y colegios, se erigían como lugares de producción de un saber escolástico e institucionalizado. Y, al mismo tiempo, sus miembros no dejaron de tener una presencia destacada en las academias y círculos eruditos que habrían de proliferar a partir del siglo XVII y que, muchas veces, se convirtieron en âmbitos en los que cultivar saberes alternativos $^{20}$.

\footnotetext{
19 FEBVRE, Lucien; MARTIN, Henri-Jean. O aparecimento do livro. Lisboa: Fundação Calouste Gulbenkian, 2000, p. 232.

${ }^{20}$ PALOMO, Federico. Clero y cultura escrita en el mundo ibérico..., p. 13.
} 
Nesse sentido, se percebe o fato mencionado por Bellini (2011) e por Palomo (2014) ao dizerem que existia essa percepção entre os religiosos de que havia uma necessidade de registrar a história. Por esse viés, isso possa delinear-se como um dos motivos que levou frei Paulo do Rosário a ter redigido sua relação, embora não seja uma explicação definitiva, pois como o próprio autor nos informa, havia outros clérigos naquele momento com ele durante a invasão, e, até onde se sabe não se conhece nenhum outro relato sobre tais batalhas, escritos por esses outros clérigos. Talvez possa ter havido outros escritos sobre estes acontecimentos, mas que desconhecemos hoje.

No que se refere ao conteúdo da obra, pelo fato de ter sido escrita em forma de relação breve, o livro não possui divisões em capítulos, tópicos, partes e nem sumário. Ele consiste numa narrativa contínua do começo ao fim, embora possua um anexo formado pela lista com o nome das companhias que serviram durante os dias de conflito, além de ter listado o nome dos soldados mortos e feridos em cada companhia. Embora não haja uma divisão de conteúdo fornecida pelo autor, a obra pode ser repartida para facilitar o seu estudo. As primeiras páginas corresponderiam a uma espécie de introdução, com um discurso que mescla um sermão com um panegírico.

Três cousas essenciais, se haõ de achar em hu[m] Capitaõ pera ter felices sucessos, zelo da hõra de Deos, madureza no discursar, \& resolução em obrar no q[eu] ouuer discursado. Todas estas cousas se acharaõ no mais perfeito General, $\mathrm{q}[\mathrm{eu}]$ relataõ as divinas letras ${ }^{21}$.

Podemos interpretar o discurso de Rosário da seguinte forma: "Zelo da honra de Deus", defender a palavra e a lei do Senhor e de sua Igreja. "Madureza no discursar", ter sabedoria, maturidade e sensatez ao se pronunciar. "Resolução em obrar no que houver discursado", saber agir como planejado, ter determinação, diligência e perspicácia em executar o que foi dito. Essas três qualidades enumeradas por Rosário, eram a seu ver, virtudes que um "general cristão" deveria possuir. No restante da primeira página e da segunda, ele continuou com seu sermão, dessa vez apresentando três homens, os quais segundo ele foram detentores dessas virtudes.

Estes homens foram Judas Macabeu, o qual zelou pela honra de Deus ao defender Israel, o patriarca Abraão que teve sabedoria ao discursar sobre o rapto de seu sobrinho Ló, e São Bernardo de Claraval, conhecido por incentivar a Segunda Cruzada (1145-1149) e defender o reconhecimento oficial da Ordem dos Templários. Assim, para Rosário, Bernardo soube ser resoluto em seus atos. Estes homens representam a escolha do autor para servirem de modelos pelos quais os leitores poderiam tomar como referencial, pois, "com efeito, a literatura religiosa é em grande parte inspirada pelo propósito de edificar, persuadir, condicionar o público letrado, ou

${ }^{21}$ ROSÁRIO, Paulo do. Relaçam breve e verdadeira da memorável victoria, que ouve o Capitão-mor da Capitania da Paraíba Antonio de Albuquerque, dos Rebeldes de Olanda, que são vinte naus de guerra, $e$ vinte e sete lanchas: pretenderão occupar esta praça de sua Magestade, trazendo nelas pera o efeito dous mil homens de guerra escolhidos, a fora a gente do mar. Lisboa: impresso por Jorge Rodrigues, 1632 , p. 1. 
de municiar ideologicamente os pregadores e catequistas para obterem um efeito concertado junto ao público iletrado"22.

Entretanto, o autor não mencionou esse sermão apenas no intuito de promover a fé católica, mas o utilizou como forma de enaltecer a pessoa de Antônio de Albuquerque Maranhão, capitão-mor da Paraíba durante a época das invasões holandesas. Aqui se percebe uma característica panegírica presente no discurso da obra. A ideia da história que gira em torno dos "grandes homens" é uma característica antiga da narrativa histórica. E no caso da história da guerra, tais homens encarnavam as figuras dos "heróis de guerra" e dos "grandes generais". Logo, Antônio de Albuquerque Maranhão, na opinião de Rosário teria sido esse "grande homem" que, com honra e nobreza, conservou as três virtudes anteriormente mencionadas, e com elas conseguiu defender à Capitania da Paraíba.

Todas as cousas acima referidas, cõ q a poderosa maõ de Deos enriq[ue]ceo \& hõrou aos perfeitos Generais, assi Sãtos, como $\mathrm{Ge}[\mathrm{n}] \mathrm{tios}$. Repartio liberalmente cõ o nosso Capitaõ mór Antonio de Albuquerq[ue], e cujo sugeito se acharaõ a hum tempo zelo da hõra de Deos \& sua Mãy sãtissima, de que he mui devoto, virtude digname[n]te erdada de seu pay Ieronymo de Albuquerq[ue], cõ a qual sempre venceo inimigos de nossa S. Fê, se[m] nunca ser vencido ${ }^{23}$.

Essa exaltação à pessoa do governador indica-nos, também, ser uma prática panegírica, pois embora fosse comum enaltecer os grandes líderes, a Relaçam Breve e Verdadeira torna Antônio de Albuquerque seu herói máximo, quase como se esse fosse uma das propostas de seu discurso. Após o "sermão introdutório", apresentado as virtudes de um "general cristão" e fazendo alusão à pessoa de Antônio de Albuquerque Maranhão, Rosário prossegue falando de algumas doações que o governador fez a igreja de Nossa Senhora das $\mathrm{Neves}^{24}$, para os festejos em sua celebração, realizados no dia 5 de agosto.

Concluído essa parte ele inicia sua narrativa acerca da guerra, comentando sobre as notícias de um possível ataque à Paraíba, $e$ as medidas que o governador tomou. No ano de 1629, o tenente-coronel Hendrik Cornelissen Lonck, que liderava a nova expedição neerlandesa ao Brasil, entre as ordens delegadas pelo Conselho dos XIX se encontrava o plano de atacar a Capitania da Paraíba, caso houvesse malogro na tentativa de se tomar Olinda, capital da Capitania de Pernambuco. O ataque a Olinda se sucedeu em 1630, e o exército holandês saiu-se vitorioso. Com essa vitória os planos de atacar a Paraíba foram adiados por alguns meses.

Embora a invasão holandesa da Paraíba tenha ocorrido em dezembro de 1631, meses antes de se oficializar a expedição, tanto os holandeses quanto os portugueses já vinham se preparando para um eventual conflito. Frei Paulo do Rosário nos relata que o capitão-mor e governador Antônio de Albuquerque Maranhão preocupado

\footnotetext{
${ }^{22}$ SARAIVA, Antônio José. História da literatura portuguesa. 16a ed. Lisboa: Porto Editora, 1993, p. 527.

${ }^{23}$ ROSÁRIO, Paulo do. Relaçam breve e verdadeira..., p. 32.

${ }^{24}$ A qual é a padroeira da capital e do estado da Paraíba.
} 
com a defesa da sua capitania, especialmente no que dizia respeito à barra do rio Paraíba, principal rio e rota fluvial até a capital, decidiu reforçar suas defesas.

Não parou aqui o zelo do prudente Capitaõ, antes vendo q[ue] a força do Cabedelo era tã pequena, \& limitada \& q[ue] a artilheria q[ue] tinha da conta, era sò aq[ui] sua indústria ahvia alcãsado del Rei, tornou de novo a importunar Sua M. que provese esta praça cõ mais artilheria \& munições no entre tanto q[ue] vinhaõ, segundo já tinha auizo de Sua M. se resolueo \& determinou e fazer hum forte nouo de 4 baluartes fabricado de torraõ \& faxina ${ }^{25}$.

$\mathrm{Na}$ ocasião, a barra do rio Paraíba dispunha apenas do Forte do Cabedelo, construção existente desde o final do século XVI, tendo passado por várias reformas desde então. No entanto, o forte que hoje conserva suas muralhas de pedra, naquele tempo das invasões ainda possuía suas muralhas feitas de torrão e faxina, nos dizeres do frei, o que significava que era feito de terra e revestido de madeira. A ordem para se construir uma nova fortificação para auxiliar o Forte do Cabedelo foi uma medida urgente, pois, como salientado por Rosário, a defesa fornecida pelo Forte do Cabedelo não seria suficiente para proteger a entrada do rio. Em setembro de 1631 estavam parcialmente concluídas as obras do Forte de Santo Antônio, construção erguida na margem oposta ao Cabedelo, no que hoje é o distrito de Costinha em Lucena.

Originalmente o novo forte deveria dispor de quatro baluartes, mas devido à pressa para se realizar as obras, apenas dois baluartes ficaram concluídos para aquele ano. Tanto o Forte do Cabedelo quanto o de Santo Antônio eram feitos de "torrão e faxina", e seguiam o modelo arquitetônico vigente da época: o baluarte fortificado ou bastião angular. Mas além de construir um novo forte, o governador Antônio de Albuquerque ordenou que o Reduto da Restinga, pequena fortificação localizada na ilha da Restinga, fosse reforçado para fornecer apoio aos dois fortes, criando assim um "triângulo defensivo" na foz do rio Paraíba (ver. figura 2).

${ }^{25}$ ROSÁRIO, Paulo do. Relaçam breve e verdadeira..., p. 3. 


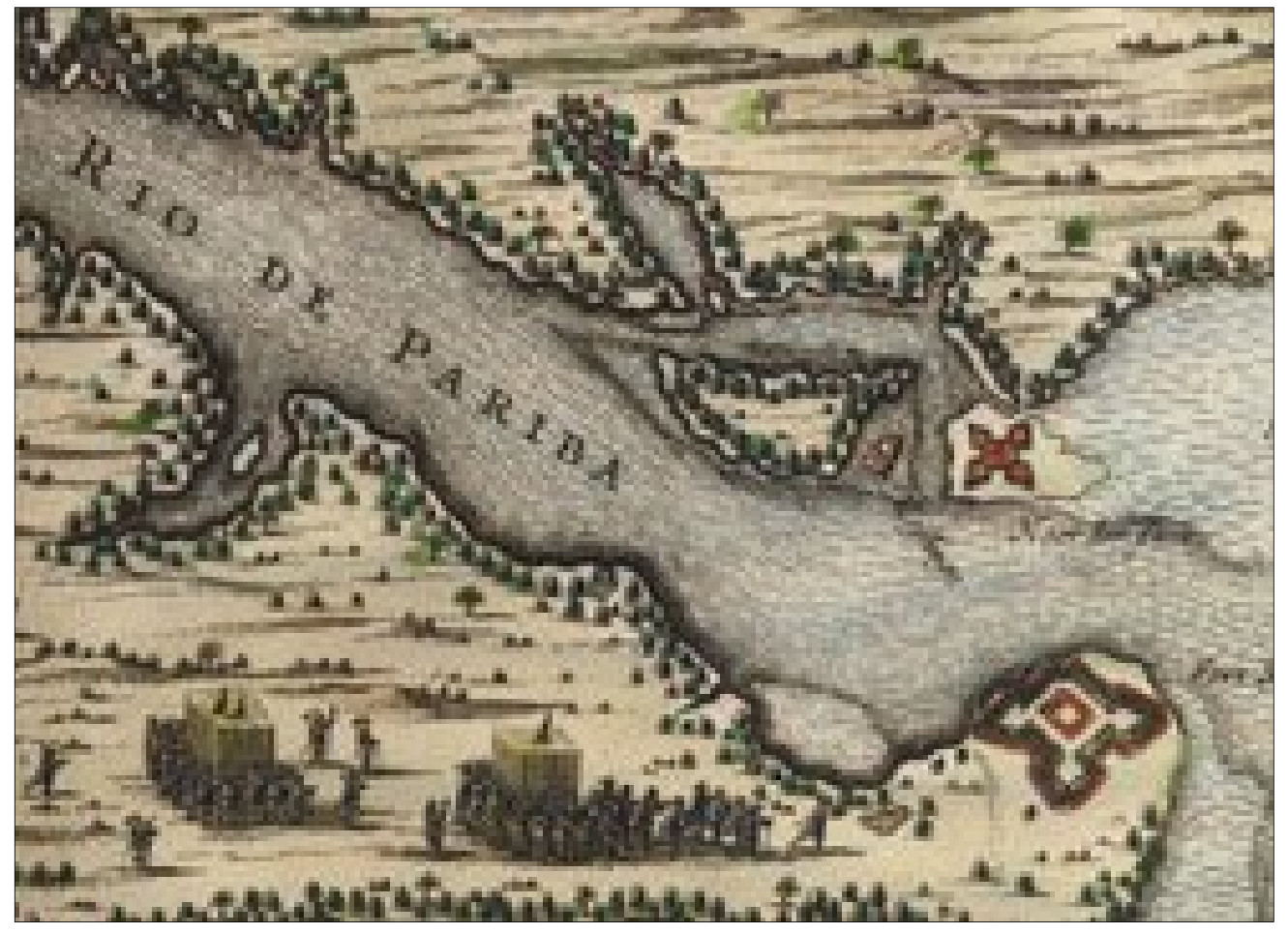

Figura 2: O "triângulo defensivo" da barra do rio Paraíba. Mapa Afbeeldinghe van Pariba enden Forten (Representação da Paraíba e seus fortes). Desenhado por Claes Jansz Visscher, editado por Nicolas Jansz Visscher. c. 1634-1635. Fonte: Cópia digital da Biblioteca Nacional Digital, Lisboa. Gravura a água-forte, 1 carta impressa em papel; $27,4 \times 36,2 \mathrm{~cm}$ em folha de $28 \times 36,6 \mathrm{~cm}$.

Frei Paulo do Rosário prossegue assinalando que ainda no mês de setembro chegou uma caravela do Reino, trazendo o capitão Antônio Figueiredo de Vasconcelos, o qual trazia uma companhia de soldados, munição, armas e oito canhões de bronze, os quais foram postos no novo forte. Além da companhia portuguesa de Vasconcelos, veio também uma companhia espanhola, comandada pelo capitão português Manoel Godinho.

A frota holandesa a qual segundo Rosário era formada por 2.000 homens, 20 navios de guerra e 27 lanchas de apoio ${ }^{26}$, atracou diante da costa do Cabo Branco na manhã da sexta-feira, de 5 de dezembro do ano de 1631, iniciando uma campanha que duraria uma semana de intensos conflitos na região do Cabedelo. Os conflitos se desenrolaram do dia 5 ao dia 12, havendo dezenas e centenas de mortos e feridos, embora que frei Paulo do Rosário não informou um número para as baixas dos

${ }^{26}$ Segundo Joannes de Laet, o número de soldados era cerca de 1.600 , os quais seguiam divididos em 13 companhias as quais eram transportadas em 16 navios. Neste caso é importante salientar que Laet foi diretor da Câmara de Amsterdã, e um "historiador" a serviço da WIC. LAET, Joannes de. Historia ou Annaes dos Feitos da Companhia Privilegiada das Indias Occidentaes desde seu começo até o fim do anno de 1636, vol. VI [1920]. Traduções de José Hygino Duarte Pereira e Pedro Souto Maior. In: Annaes da Biblioteca Nacional do Rio de Janeiro, 30, 33, 38, 41-42. Rio de Janeiro: Officinas Graphicas da Bibliotheca Nacional, 1912-1925,13v., p. 18. 
holandeses, mas informou que para o lado luso-espanhol houve 83 feridos e 65 mortos $^{27}$.

Em seu relato o frei beneditino nos forneceu alguns detalhes sobre as batalhas diárias, destacando alguns dias do conflito, o primeiro dele foi 8 de dezembro, dia de Nossa Senhora da Conceição.

Veyo o dia felice da Conceição da Virgem Raynha dos Anjos, \& se este foy alegre ao mundo, quando foy concebida no ventre de Sancta Anna sua mãy, naõ menos o foi ao nosso quartel pella nova da Caravella de socorro de poluora \& muniçoens, auer escapado ao inimigo, \& serentrada no Màmàgope Rio, que está sinco legoas do nosso quartel, porque se vestiraó todos de esperanças muy certas, de que a Virgem que a guardara, era pera nos dar victoria incredível ${ }^{28}$.

Rosário tomou aquele dia como sendo uma benção dada por Nossa Senhora das Neves aos seus devotos fiéis ${ }^{29}$. Essa atitude do frei não foi a única registrada na historiografia sobre o período holandês ${ }^{30}$.

$\mathrm{Na}$ mesma ora que chegarão os valerosos hespanhoes cõ a corage $[\mathrm{m}] \mathrm{q}$ trazião, \& desejosos de pelejar, se forão ao inimigo q estava muy vizinho nosso, travando cõ eles hu[m]a escaramuça \& bateria tam renhida, q empenhou todo o quartel: acudirão todos á briga cõ determinada resolução \& pelejarão cõ tal corage [m], q foy forçado ao inimigo retirarse a suas trincheiras, com perda de muita ge[n]te, se q da nossa ounesse alguma ferida, ou morta ${ }^{31}$.

Embora Rosário diga que os reforços chegados tiveram em muito a contribuir nos confrontos daquele dia, isso não foi o bastante para fazer o inimigo recuar, pois em seu relato ele prossegue dizendo que os holandeses mantiveram seus ataques, principalmente usando os canhões nas trincheiras para bombardear o forte, enquanto seus soldados defendiam seus postos de ataque.

${ }^{27}$ Para mais informações sobre os números de mortos e feridos, com base nos dados fornecido por frei Paulo do Rosário, mas também por outros relatos da época, consulte a Tabela I em Guerras lusoholandesas na Capitania da Paraíba. 2016, p. 208.

${ }^{28}$ ROSÁRIO, Paulo do. Relaçam breve e verdadeira..., p. 8.

${ }^{29}$ Maravall salientou que era uma característica do discurso religioso do Barroco, o apelo ao divino para se solucionar calamidades. Entre os católicos recorria-se aos santos, Nossa Senhora e a Jesus, já os protestantes recorriam diretamente a Deus. MARAVALL, José Antônio. A cultura do Barroco: Análise de uma Estrutura Histórica. Tradução Silvana Garcia. São Paulo: Editora da USP, 2009. (Clássicos, 10), p. 126-127.

${ }^{30}$ Evaldo Cabral menciona as manifestações religiosas promovidas por importantes figuras da época como Manoel Calado, Rafael de Jesus e Diogo Lopes Santiago, os quais relataram em suas obras, manifestações e aparições divinas da Virgem Maria e de santos nos campos de batalhas das guerras luso-holandesas. MELLO, Evaldo Cabral de. Rubro Veio: o imaginário da restauração pernambucana. 3 ed. São Paulo: Alameda, 2008.

${ }^{31}$ ROSÁRIO, Paulo do. Relaçam breve e verdadeira..., p. 9. 
O capitão-mor Antônio de Albuquerque ordenou que reparos às defesas do forte fossem feitos, além da construção de uma nova trincheira e de um hornaveque (estrutura defensiva em forma de triângulo, geralmente escavada ou na forma de muro), os quais tiveram a construção supervisionada pelo engenheiro Diogo Paes, o qual havia chegado com as companhias espanholas naquele dia. Apesar desses reforços isso não inibiu os holandeses de se arriscarem em novos ataques. A "Batalha do dia 8" seguiu-se acirrada pelo restante da tarde, estando as duas frentes inimigas lutando quase em pé de igualdade, embora que Rosário e Coelho digam que a vitória naquele dia foi para o lado luso-espanhol. No dia 9 de dezembro, frei Paulo do Rosário prosseguiu dizendo que:

Muito se enganarão os Rebeldes cõ os leões de Espanha, q[ue] não costumão a empre[n]der cousas, se[m] q[ue] as leve[m] ao devim fim. Começou a crecer a obra q[ue] se fez cõ grande calor, \& não menos alegria, de ver q[ue] o inimigo se ressentia tanto dela: \& asi toda a ge[n]te do quartel se[m] se reparar em grao estado, ou calidade, acarretarão faxina pera a obra crecer em breue, em q[ue] deu notáveis exe[m]plos o nosso Capitão mór; porq[ue] cõ andar em hu[m]a viua roda de negócios, \& diuirtido em tam varias cousas como a guerra tras consigo, não faltou em ser $o$ primeiro que nos deu exemplos raros de zelo do serviço del Rei, com que obrigou atê aos Sacerdotes, \& Religiosos que asistissimos a imitar tam raro exemplo ${ }^{32}$.

Nesse comentário o frei destacou o empenho e a virtude do capitão-mor Antônio de Albuquerque em incentivar a moral do exército, no que conseguiu preparar o forte para o segundo ataque das tropas inimigas naquele dia. De acordo com a Relação Breve, mesmo o inimigo tendo sofrido algumas baixas devido ao fogo dos canhões, ainda assim, eles estavam determinados a não recuar novamente. $\mathrm{O}$ autor relata que essa batalha foi acirrada e agressiva.

No dia 10 de dezembro ocorreu a mais sangrenta das batalhas até então, segundo dito por Rosário. Os holandeses munidos com escadas correram em direção aos muros no intuito de escalá-los, mas foram repelidos com chuva de balas. Rosário narra que o inimigo estava em maior número, com mais armas, munição e atacou por três frentes o forte do Cabedelo, mas ainda assim, os portugueses defenderam-se de forma heroica. Rosário escreveu o seguinte:

Incredível foy o valor com que se teue o encontro a raro puxante inimigo, \& em tam repentino assalto; porque com estarem desarmados os mais dos nossos, se batalharão com os Rebeldes de maneira que mais parecião leões desatados do que homens que peleijavão, com tal desigual partido de gente, armas, \& munições. Se ouuer de dizer as particulares

\footnotetext{
${ }^{32}$ ROSÁRIO, Paulo do. Relaçam breve e verdadeira..., p. 9.
} 
valentias que nesta orà se obrarão, mais ouuera fazer Chronica que Relação abreuiada ${ }^{33}$.

Rosário narra que os feitos de guerra foram tantos e tão grandiosos, que se ele fosse relatar tudo o que ocorreu naquele fatídico dia, teria que escrever uma crônica e não uma relação, pois as crônicas eram um estilo literário mais extenso, diferente das relações, as quais eram conhecidas por sua objetividade e brevidade. Todavia, ele salienta que a derrota sofrida no dia 10, foi determinante para levar os holandeses a desistir da campanha. Pois embora alguns ataques pontuais ocorreram no dia 11, nesta mesma data, foi dado a ordem para retornar as tropas aos navios.

Pela madrugada do dia 12, o exército holandês já havia deixado o acampamento, se encontrando de volta aos navios. De manhã, em terra, alguns batedores portugueses perceberam o silêncio no acampamento inimigo, então retornaram ao forte e avisaram ao governador Antônio de Albuquerque sobre o ocorrido. $\mathrm{O}$ governador reuniu uma tropa e seguiu com essa até o acampamento holandês. Lá se constatou que o local havia sido abandonado na calada da noite, tendo os holandeses agidos de forma silenciosa e rápida como salientou Rosário, dizendo que os holandeses pareciam ter "asas nos pés", pois de forma surpreendente e sem barulho, conseguiram evacuar todas as companhias para os navios. Quando Antônio de Albuquerque chegou com sua tropa à praia, a areia estava revirada devido à intensa movimentação. Os holandeses deixaram munição, balas de canhão, pás, enxadas, mantimentos e outros objetos ficaram para trás ${ }^{34}$.

A frota permaneceu ali ancorada pelo restante do dia, aguardando ventos favoráveis para seguir viagem. Pela tarde, eles partiram, no entanto, sem deixar de tentar um último ataque. Três navios e duas lanchas foram despachados em direção ao rio Mamanguape, segundo informou frei Paulo do Rosário ${ }^{35}$. Duarte de Albuquerque Coelho ${ }^{36}$ informou que foram três navios e seis barcaças enviadas com o intuito de atacar as caravelas do capitão Luiz Pinto de Matos, ancorada na foz do Mamanguape. Havendo percebido que tais embarcações se dirigiam ao norte, o capitão-mor decidiu tomar medidas urgentes:

Com incredível presteza: acudio o Capitão mòr Antonio de Albuquerque, ordenando ao Capitão Pedro Marinho de Cubera, que lhe fosse estrouar o intento. Esteue este Capitão de outra banda fronteiro ao Cabedelo com artilheria \& gente em hum reduto que o Capitão mòr Antonio de Albuqurque ordenou que fizesse. [...]. Acudio logo com muita pressa como fica dito, o Capitão Pedro Marinheiro a resistir aos inimigos que se foy sem nenhum fruito pera o Recife de Pernambuco, \& sem leuar nenhum despojo ${ }^{37}$.

\footnotetext{
${ }^{33}$ ROSÁRIO, Paulo do. Relaçam breve e verdadeira..., p. 12.

${ }^{34}$ ROSÁRIO, Paulo do. Relaçam breve e verdadeira..., p. 14.

${ }^{35}$ ROSÁRIO, Paulo do. Relaçam breve e verdadeira..., p. 14.

${ }^{36}$ COELHO, Duarte de Albuquerque. Memorias diarias de la Gverra del Brasil, por discurso de nueve anos, empeçando desde M. DC. XXX. Madrid: impresso por Diego Diaz de la Carrera, 1654, p. 71.

${ }^{37}$ ROSÁRIO, Paulo do. Relaçam breve e verdadeira..., p. 14.
} 
Embora a primeira expedição holandesa à Capitania da Paraíba houvesse fracassado, nos dias seguintes, o capitão-mor Antônio de Albuquerque manteve-se em cautela, pois se suspeitava que um novo ataque pudesse ocorrer. No dia 21 de dezembro avistou-se ao longo da costa do Cabo Branco uma nova armada holandesa, a qual já era aguardada, pois de acordo com o frei, o comandante Matias de Albuquerque Maranhão (irmão do governador da Paraíba) havia recebido a informação de um desertor francês que servia a WIC, o qual contou que no Recife estava-se preparando uma nova expedição.

O governador Antonio de Albuquerque foi avisado e ordenou que quatro disparos de alerta fossem dados. O silêncio noturno foi rompido com o trovejar das peças de artilharia, pondo os fortes e o reduto da Restinga em prontidão. Na tarde do dia 21 , avistou-se a frota inimiga. Ambrósio Richshoffer ${ }^{38}$ o qual participou daquela expedição, conta-nos que ela era liderada novamente pelo coronel Steyn-Callenfels e o major Berstedt, dispondo de 19 companhias e 14 navios.

A nova armada neerlandesa era avistada na costa do Cabo Branco. A tensão dos dias anteriores retornou, no entanto, a missão da nova armada era atacar a cidade de Natal, capital do Rio Grande. Antônio de Albuquerque Maranhão tendo notado que os holandeses não pretendiam atacá-los novamente, mas cogitando que o alvo seria a capitania vizinha no Norte, enviou seu irmão para lhes fornecer apoio. A tropa de Matias de Albuquerque Maranhão chegou poucos dias depois para reforçar as defesas do forte, embora que os holandeses acabaram desistindo de atacá-lo antes disso.

\section{Os discursos na Relaçam breve e verdadeira:}

Vimos algumas características gerais da obra e alguns comentários acerca de seu conteúdo histórico, referente à primeira expedição holandesa à Capitania da Paraíba, já que o autor também aborda ainda de que forma sumária, a primeira expedição à Capitania do Rio Grande, a qual não foi tema de nosso estudo. De qualquer forma, nesta parte final do artigo, comentaremos algumas características mais especificamente sobre os discursos de frei Paulo do Rosário: o discurso religioso, político e panegírico.

No século XVII, a produção literária portuguesa vivenciava sua fase barroca, a qual compreendeu o período entre 1580 a 1750 . Sendo que a influência do barroco literário chegou a Portugal pela Espanha, e neste aspecto, o barroco português resguarda muitas similaridades com o espanhol.

Posto isso, pergunta-se: quais as características fundamentais da estética barroca? Primeiro que tudo corresponde à tentativa de fundir, numa unidade ambiciosa de simbolizar a suma perfeição, as duas linhas de força que conduziram o pensamento europeu ao longo do século XVI: o Barroco procurou conciliar numa síntese utópica a visão de mundo

\footnotetext{
${ }^{38}$ RICHSHOFFER, Ambrósio. Diário de um soldado da Companhia das Índias Ocidentais (1629-1632). $2^{a}$ ed. São Paulo/Brasília: IBRASA/INL, 1978, p. 101.
} 
medieval, de base teocêntrica, e a ideologia clássica, renascentista, pagã, terrena, antropocêntrica ${ }^{39}$.

Para além dessa característica de unidade proposta por Massaud Moisés (2008), a escrita barroca ganhou também tom político, principalmente influenciado pelo movimento da Contrarreforma. No que por sua vez, os autores católicos em alguns casos de forma mais direta e contundente, claramente faziam críticas às igrejas protestantes, e no caso de frei Paulo do Rosário essa crítica, essa ideologia da Contrarreforma estava presente. É visível essa sua indignação com os holandeses protestantes, os quais ele considerava como desviados da "verdade cristã", "rebeldes da Igreja" e até mesmo os chamou de "seguidores da serpente", uma alusão ao Pecado Original.

Aqui se confirmarão de todos a esperanças da victoria por orde[m] da Mãy de Deos, porq[ue] que veyo ao mundo a vencer a serpente infernal, a que a Virge[m] atr[o]pelleou, como o Spiritu Santo o tinha dito, ipsa conteret caput tuum, não permitindo que no seu dia nos fizesse algum dano os sequaces da serpente, nos assegurou na victoria que deles auiamos de ter com seu fauor, \& ajuda ${ }^{40}$.

Nesta citação se pode notar tanto o posicionamento contrário aos protestantes, como também se pode ler o discurso religioso no que concerne numa espécie de "providência", ou seja, que a primeira invasão holandesa segundo frei Paulo do Rosário, teria sido um tipo de "provação" enviada pelos Céus para testar seus fiéis. No entanto, esse posicionamento religioso não foi algo exclusivo da escrita de Rosário por ele ter sido um clérigo, mas de acordo com o historiador português Antônio José Saraiva, a produção literária portuguesa do século XVII foi marcada por uma cultura religiosa propagandista que estava em alta.

A produção literária mais abundante em Portugal neste período foi certamente a de propaganda e edificação religiosa: sermões, hagiografias, tratados moralistas, etc. Prolonga-se a corrente que apontámos já no século XVI, porque permanecem as circunstâncias que lhe dão origem: importância numérica da população eclesiástica, controle dos meios de difusão da cultura pelas ordens religiosas, orientação neo-escolástica das universidades, rigidez hierárquica e ideológica ligada à repressão inquisitorial e a uma formalística devoção popular ${ }^{41}$.

\footnotetext{
${ }^{39}$ MOISÉS, Massaud. A literatura portuguesa. $37^{a}$ ed. São Paulo: Cultrix, 2008, p. 111.

${ }^{40}$ ROSÁRIO, Paulo do. Relaçam breve e verdadeira..., p. 12.

${ }^{41}$ SARAIVA, Antônio José. História da literatura portuguesa..., p. 572.
} 
Embora a obra de Rosário não seja um sermão, nem uma hagiografia ou um tratado moralista, seguindo aqui os exemplos dados por Saraiva, sua relação sobre as invasões às capitanias da Paraíba e do Rio Grande possui características moralistas e edificantes que são esboçadas no seu discurso religioso pelo qual ele interpretou aquelas batalhas. Além disso, Rosário não foi o único a redigir um relato de guerra com esse tom religioso. Frei Manoel Calado do Salvador (1584-1654) autor de O Valeroso Lucideno e o Triunfo da Liberdade na Restauração de Pernambuco (1648), assinalou logo no começo de seu livro, que entendia a conquista e destruição de Olinda, como tendo sido uma "punição divina" 42.

Para Manoel Calado, cujo pensamento era baseado nas interpretações bíblicas, os feitos, históricos ou não, eram, em sua ocorrência natural e mecânica, resultados de uma Providência divina. A identidade divina está presente enormemente nos esquemas alegóricos dos escritos seiscentistas. A religião ocupava um posto central para os homens do século XVII, fossem eles católicos ou protestantes ${ }^{43}$.

Da mesma forma que os mouros invadiram Portugal e Espanha ainda na Idade Média, cuja invasão foi considerada uma praga aos católicos, às invasões holandesas foram tomadas por alguns como um acontecimento similar. Aqui se nota, tanto no relato de Calado, quanto no de Rosário, esse sentimento antirreformista, o qual Moisés (2008) e Saraiva (1993) assinalaram como fazendo parte do pensamento geral naquela época, em nações como Portugal e Espanha.

Além de Calado, outros religiosos como Antônio Rosado, Diogo Lopes de Santiago, autor de História da Guerra de Pernambuco (1654), Simão de Vasconcelos, Antônio Vieira e Rafael de Jesus, autor do Castrioto Lusitano (1679), foram alguns dos quais compartilharam essa visão providencialista acerca das invasões holandesas no Brasil ${ }^{44}$. No entanto, frei Paulo do Rosário foi o único no quesito de ter escrito algo especificamente sobre a Capitania da Paraíba. Mas, além desse discurso antirreformista, a obra de Rosário guarda outras características religiosa, pois como visto anteriormente, ele procurou transmitir valores morais cristãos, algo que consiste em uma das características literárias da escrita barroca daquela época. "O Barroco caracteriza-se pelo objectivismo, pela pompa, pelo exibicionismo material do poder e da fé" 45 .

Esse "exibicionismo material do poder e da fé" do qual Antônio Saraiva fez menção, se encontra em ambos os casos na obra de Rosário. No caso da fé, essa é visível ao longo da narrativa, mas principalmente no começo dela, como será

${ }^{42}$ CALADO, Manoel. O Valeroso Lucideno e Triunfo da Liberdade. Lisboa: por Paulo Craesbeeck, 1648, p. 8.

${ }^{43}$ BRITO, Sylvia Brandão Ramalho de. A dialética do castigo: histórias de um frade no Brasil holandês. 2012. 175 f. Dissertação (Mestrado em História) - Programa de Pós-Graduação em História, Universidade Federal da Paraíba, João Pessoa, 2012, p. 73.

${ }^{44}$ MELLO, Evaldo Cabral de. Rubro Veio..., p. 220-236.

${ }^{45}$ SARAIVA, Antônio José. História da literatura portuguesa..., p. 459. 
explicado adiante. No caso do poder, esse é representando nos valores da honra, coragem, força, disciplina, determinação e lealdade nas figuras dos comandantes $e$ dos soldados. Por sua vez, ambas as características refletem a opinião de Saraiva ${ }^{46}$, que um dos papéis da escrita barroca era de proporcionar uma "propaganda de edificação religiosa".

Quando percebemos a menção do autor a Abraão, Judas Macabeu, São Bernardo e Nossa Senhora das Neves, observa-se esse discurso de "propaganda e devoção", pois consistiu numa forma de reafirmar a identidade dos portugueses e espanhóis com a doutrina católica, ainda mais numa época de guerras entre católicos $e$ protestantes, período bastante sangrento na história do continente europeu.

No segundo caso, nota-se um discurso de lealdade à Coroa Espanhola. Rosário não se refere aos invasores os chamando pelo gentílico de holandeses, flamengos, neerlandeses ou batavos, mas os chamava apenas de rebeldes: "os rebeldes de Holanda", que parte de dois motivos: o primeiro, já foi retratado na introdução, no qual consistiu em cunho político, devido à insubordinação dos holandeses a Coroa Espanhola.

Embora Rosário fosse um português de nascença, ele se considerava um súdito leal do rei de Espanha, que na época era Filipe IV, e essa sua identificação com a soberania de um rei estrangeiro se revela no livro, nas várias referências que ele faz aos capitães e comandantes serem fiéis e devotos súditos de Sua Majestade, como também menciona que os holandeses enfrentariam a "força da Armada de Espanha" e a "bravura dos leões de Espanha". Logo, ele toma para si essa desavença entre espanhóis e holandeses, englobada com a Guerra dos Oitenta Anos, mostrando que os portugueses eram súditos fiéis, ao contrário dos holandeses, que eram "rebeldes" e "traidores".

Quanto ao discurso político de frei Paulo do Rosário, esse é menos presente em sua obra do que o discurso religioso, por sua vez, o discurso panegírico encontra-se no mesmo estado, surgindo no começo do livro e depois e em algumas partes da narrativa. Vimos que na introdução da obra, quando o autor fala sobre as virtudes que um "general cristão" deveria possuir, e depois de apresentar essas virtudes e apresentar três exemplos que a respaldavam, ele diz que o então governador $e$ capitão-mor da Paraíba, Antônio de Albuquerque Maranhão, foi um homem que possuiu estas qualidades, inicia-se assim, esse viés panegírico da Relaçam breve e verdadeira.

Embora não tenha sido algo incomum na época, pois no que se refere à produção histórica acerca do Brasil holandês, os livros Valeroso Lucideno (1648) e o Castrioto Lusitano (1679) são panegíricos a João Fernandes Vieira (c. 1613-1681), um dos importantes nomes da Restauração Pernambucana (1645-1654). Ademais, as próprias Memórias Diárias da Guerra do Brasil (1654), possui também um tom panegírico, seja por parte do autor Duarte de Albuquerque Coelho, enaltecendo sua iniciativa em ter redigido aquele livro para Sua Majestade o rei Filipe IV, ou fosse falando da dedicação e desempenho de seu irmão, o general Matias de Albuquerque [Coelho] e de outros fidalgos.

${ }^{46}$ SARAIVA, Antônio José. História da literatura portuguesa..., p. 527. 
É importante observar que a razão do louvor, para os autores de panegíricos, nunca deve ser o simples desejo de louvor, que poderia desqualificar o seu discurso como adulação baixa, mas sim a produção de exemplo virtuoso para a emulação das pessoas, de modo que a imitação dos melhores servisse ao propósito de superação excelente da condição particular e de reforço da concórdia e da saúde do organismo do Estado ${ }^{47}$.

De acordo com os argumentos de Alcir Pécora, podem-se identificar algumas dessas características, que estão presentes na Relaçam Breve e Verdadeira. Frei Paulo do Rosário não somente redigiu seu relato "breve e verdadeiro" a respeito de um acontecimento real, o qual foi a primeira invasão holandesa à Paraíba, mas também aproveitou para destacar em seu discurso elementos panegíricos que enaltecessem a figura do capitão-mor da Paraíba, Antônio de Albuquerque Maranhão.

Pécora diz que o panegírico produz um discurso virtuoso que sirva de exemplo, para que outros possam emular ou tomar como modelo. No começo da relação, Rosário já inicia a homenagem a Antônio de Albuquerque, comparando-o ao que ele considerava serem "grandes homens". Nesse ponto ele não apenas fornece ao leitor um exemplo, mas quatro exemplos, pois enquanto ele compara o governador às figuras de Judas Macabeu, Abraão e São Bernardo, ele também está afirmando que tais homens são dignos de exemplo, e por isso foram escolhidos para serem os modelos.

Não obstante, entre algumas das virtudes mencionadas por Rosário, destacam-se o zelo, a prudência, a honra, a coragem, a confiança, a determinação, a diligência e a lealdade. Essas são algumas das virtudes das quais o autor procurou transmitir ao leitor. E de acordo com Leite (2009), tais virtudes consistiam numa espécie de parâmetro, de senso comum, nos séculos XVI e XVII, algo que ele analisou em folhetos militares da época da ocupação holandesa no Brasil.

Todavia, o leque de valores transpunha frequentemente os limites dos movimentos bélicos, alcançando também virtudes cristãs e, particularmente, católicas. Guerra e religião, aspectos não desassociados naquele tempo. Dessa forma, a conduta exemplar exposta nos folhetos analisados apresentava um homem pleno, referência de honra, fama e glória a serem emuladas. Predominava o destaque das virtudes cardeais: a prudência (que incluía a previdência, cuidado e conhecimento); a temperança (abrangendo honestidade, sobriedade e continência); o bom ânimo e a coragem (capazes de alcançar a paz); a constância e a paciência; e o senso de justiça (compreendendo liberdade, religiosidade, inocência, piedade, caridade, amizade, reverência e concórdia). Tais tributos surgiam explícita ou

${ }^{47}$ PÉCORA. A. Alcir. Rudimentos da vida coletiva. Cotia - SP: Ateliê Editorial, 2002, p. 48. 
implicitamente no corpo dos relatos de guerra, produzindo neles um significado que ultrapassava a mera notícia dos últimos acontecimentos no campo de batalha ${ }^{48}$.

Da perspectiva apresentada por Jorge Leite, o qual comenta brevemente um pouco sobre os elogios tecidos a Antônio de Albuquerque Maranhão por frei Paulo do Rosário, podemos destacar dessa lista as virtudes da prudência, bom ânimo, coragem e senso de justiça, como as que melhor se identificam com as virtudes descritas por Rosário a respeito de Antônio de Albuquerque, mas também se identificam com as três virtudes que ele menciona no começo de seu livro.

Não obstante, Pécora ${ }^{49}$ também diz que esse discurso possui a condição de reforçar a "concórdia" e a "saúde do organismo do Estado". Antônio de Albuquerque é comparado a homens religiosos, como tendo sido um "general cristão" de valor, o qual zelou pelo Catolicismo, tendo sido benevolente com a Igreja, ao doar presentes à padroeira de sua capitania. Além disso, ele era um homem que procurava manter a união e a moral em alta entre seus homens, segundo nos atestou o próprio Rosário.

No que diz respeito ao segundo aspecto mencionado por Pécora, em respeito ao Estado, Antônio de Albuquerque era governador da Capitania da Paraíba e um nobre. Ele era um homem do Estado e a serviço deste. Sua liderança nas guerras luso-holandesas na Paraíba expressam seu dever e lealdade em defender aquela capitania. Aqui se nota que ele não é apenas o governante que zela pelo seu cargo, mas também é o súdito que procura defender as terras de seu senhor. Logo, tendo ele defendido a capitania com êxito nesse primeiro ataque, expressa que ele conseguiu manter bem a "saúde do organismo do Estado" para aquela capitania. E isso é um motivo a mais para que sua pessoa merecesse louvor.

Por tais características apresentadas por Pécora e usadas como item de comparação, podemos observar que a Relaçam Breve e Verdadeira (1632), em meio a sua narrativa bélica, possui características panegíricas, embora não se saiba se isso foi algo próprio do autor, o qual quis homenagear o governador, ou o governador teria "contribuído" para que Rosário escrevesse sobre ele. Não obstante, o intuito do discurso panegírico também era reflexo da sociedade portuguesa do Antigo Regime, na qual os homens nobres ou não, procuravam ganhar recompensas do rei, as chamadas cartas de serviços ou mercês. A atribuição dessas mercês consistia num prolongamento das relações de suserania-vassalagem da Idade Média, onde os súditos para receberem algo do monarca deveriam mostrar sua lealdade a esse através de serviços, os quais seriam dignos de valor.

O próprio Rosário sugere que o governador procurava por fama, assim como, Judas Macabeu havia feito em seu tempo. Logo, essa busca por fama, elucida também a ideia de ele buscar alguma recompensa, pois afinal, ele arriscou sua vida, fazendas e homens para defender as terras da Coroa. E essa perspectiva é reforçada no final do livro, onde Rosário diz que caso o rei lê-se aquele livro, deveria conceder mercês a aqueles nobres soldados que defenderam suas terras.

${ }^{48}$ LEITE, José Luiz de Miranda. O dito e o feito: heróis exemplares nos relatos de guerra na Restauração Pernambucana (1630-1654). 2009. 168 f. Dissertação (Mestrado em História) - Programa de PósGraduação em História, Universidade Federal Fluminense, Niterói, 2009, p. 108.

${ }^{49}$ PÉCORA. A. Alcir. Rudimentos da vida coletiva..., p. 49. 


\section{Considerações finais}

Embora consista em uma obra curta, o livro do frei beneditino Paulo do Rosário, revela-se de uma especificidade única, nem tanto pelo esmero que foi escrito ou pela quantidade de informações, já que nesse sentido, o próprio autor informa que teve que fazer uma seleção a respeito do que iria contar em seu livro. Mas a Relaçam Breve e Verdadeira revelou-se como uma obra bastante importante para se estudar a história das invasões holandesas não apenas à Capitania da Paraíba, mas também a Capitania do Rio Grande, embora que seu foco seja a Paraíba.

Neste relato embora, sumário, frei Paulo do Rosário comprometeu-se em passar um testemunho quase que diário, já que o dia 7 de dezembro, ele praticamente nada comentou, no entanto, seu relato conseguiu narrar os principais acontecimentos entre os dias 5 e 12 dezembro, período no qual durou a primeira expedição dos holandeses para se conquistar a Capitania da Paraíba, que consistia como mencionado na carta de 1629, em uma das localidades chaves para os interesses da Companhia das Índias Ocidentais. No entanto, a conquista da Paraíba revelou-se numa empresa militar mais difícil que os holandeses supunham que fosse, já que foram necessárias mais duas expedições para se conseguir apossar-se daquela que era a segunda capitania que mais produzia açúcar na década de $1630^{50}$. Por isso ser uma área essencial para os interesses mercantis da WIC.

Não obstante, a Relaçam Breve e Verdadeira para além do relato histórico em si, sobre uma das várias batalhas ocorridas nas guerras luso-holandesas (1630-1654), também consiste numa fonte que nos revela os aspectos culturais e ideológicos de seu tempo, algo visto através do discurso religioso, político e panegírico. No caso do discurso religioso esse estava atrelado ao discurso político, o qual se situava no contexto do cenário da Guerra dos Oitenta Anos (1568-1648), que de certa forma, as Guerras luso-holandesas ou "Guerras do Açúcar" no Brasil, foram uma continuidade desse embate originado na Europa, que foi transferido através do Atlântico, chegando aos trópicos da América Portuguesa. Em cujo contexto, os holandeses novamente voltaram a entrar em confronto com a Coroa Espanhola, lembrando que na época devido a União Ibérica (1580-1640), o Brasil era colônia dos espanhóis.

E tal fato é refletido na forma que Paulo do Rosário se referia aos holandeses, tratando-os como "rebeldes" e "traidores", inclusive traidores também da fé, pelo fato de serem calvinistas. Algo que também encontra respaldo no contexto das guerras religiosas, o que revela o quão problemáticos foram os séculos XVI e XVII, os quais para alguns estudiosos foram épocas de crises econômicas, políticas, sociais $e$ culturais $^{51}$.

Por fim, quanto ao discurso panegírico de enaltecimento proposital ou não do capitão-mor Antônio de Albuquerque Maranhão, além de ser reflexo da cultura historiográfica de enaltecer líderes, algo que remonta desde a Antiguidade com a ideia

${ }^{50}$ GONÇALVES, Regina Célia. Guerras e açúcares: política e economia na Capitania da Parahyba, 1585-1630. Bauru: Edusc, 2007, p. 248-250.

51 HILL, Christopher. "Introduction". In: ASTON, Trevor. Crisis in Europe: 1560-1660. London: Routledge, 1965, p. 1-4. 
de historia vitae de Marco Túlio Cícero ${ }^{52}$, encontrou no livro de Rosário uma contribuição do discurso religioso da época. A comparação de Antônio de Albuquerque a "grandes homens" como patriarca Abraão, Judas Macabeu e São Bernardo de Claraval, concentra em si, todo esse discurso religioso e político pelo qual o autor conviveu. O que torna o livro Relaçam Breve e Verdadeira ao mesmo tempo num relato de guerra e num panegírico.

\section{$\operatorname{son} 2$}

\section{RESUMO}

Paulo do Rosário foi um frei beneditino português que no ano de 1631, atuando como comissário provincial, testemunhou a primeira invasão holandesa à Capitania da Paraíba, ocorrida entre 5 e 12 de dezembro. A partir de seu testemunho ele redigiu uma singular e preciosa fonte primária, um pequeno livro intitulado Relaçam Breve e Verdadeira, o qual foi publicado em 1632, em Lisboa. Nesse livro o frei relatou suas impressões a respeito da "Batalha do Cabedelo", o primeiro de três ataques realizados pela WIC para conquistar a Paraíba. A proposta desse artigo foi apresentar essa fonte ainda pouco conhecida e estudada, analisando alguns aspectos do seu discurso, pois além de ter escrito uma história da guerra, Rosário acrescentou em sua narrativa elementos religiosos, políticos e panegíricos.

Palavras-chave: frei Paulo do Rosário; Relaçam Breve e Verdadeira; Capitania da Paraíba; Brasil holandês.

Artigo recebido em 24 ago. 2016.

Aprovado em 16 mai. 2018.

\begin{abstract}
Paulo do Rosário was a portuguese frey Bento who in 1631, acting as provincial commissary, witnessed the first Dutch invasion of the Captaincy of Paraíba, held between December 5 and 12. From his testimony he wrote a singular and precious primary source, a small book titled Relaçam Breve e Verdadeira, which was published in 1632 in Lisbon. In this book the frey reported his impressions regarding the "Battle of Cabedelo", the first of three attacks by WIC to conquer Paraíba. The purpose of this article was to present this source that is still little known and studied, analyzing some aspects of its discourse. Besides writing a history of war, Rosário added religious, political and panegyric elements in his narrative.
\end{abstract}

Keywords: Frey Paulo do Rosário; Relaçam Breve e Verdadeira; Captaincy of Paraíba; Dutch Brazil.

${ }^{52}$ KOSELLECK, Reinhart. Futuro passado: contribuição a semântica dos tempos histórico. Tradução de Wilma Patrícia Maas e Carlos Almeida Pereira. Rio de Janeiro: Contraponto/Ed. PUC-RIO, 2006. 